Acta Manilana 64 (2016), pp. 25-32

Printed in the Philippines

ISSN: 0065-1370

\title{
Fluorophore-labeled bioengineered glucose binding protein for measurement of transdermal glucose
}

\author{
Cristina Tiangco ${ }^{1,3}$, Sheniqua Brown ${ }^{1,2}$ Fortunato Sevilla III ${ }^{3}$, \\ Govind Rao ${ }^{1,2}, \mathcal{E}$ Leah Tolosa ${ }^{* 1,2}$ \\ ${ }^{1}$ Center for Advanced Sensor Technology, \\ ${ }^{2}$ Department of Chemical, Biochemical and Environmental Engineering, \\ University of Maryland Baltimore County, Baltimore, MD, 21250 \\ ${ }^{3}$ The Graduate School, University of Santo Tomas, 1015 Manila, Philippines
}

\begin{abstract}
Measurement of glucose is an important component of care in the intensive care unit. Current methodologies for glucose monitoring include enzymatic-based laboratory analyzers, point of care testing and continuous glucose monitoring systems that all require breaking the skin. This study focuses on the development of a glucose biosensor to measure transdermal glucose (TG) by noninvasive passive diffusion. The H152C glucose binding protein (GBP) labeled with the polarity-sensitive dye BADAN (6-bromoacetyl-2dimethylaminonaphthalene) was prepared and characterized with the aim of producing a biosensor with an operating range at micromolar levels compatible with TG concentrations. The BADAN-labeled GBP exhibited a large fluorescence intensity increase (228\%) upon addition of a saturating concentration of glucose. The glucose binding constant was calculated to be $\left(K_{d}\right) 1.124 \pm 0.2361 \mu \mathrm{M}$. The biosensor has a linear operating range of $0.030-0.460 \mu \mathrm{M}$, making it suitable for monitoring transdermal glucose. The use of the biosensor was demonstrated by measuring TG collected by passive diffusion of glucose through the skin of healthy adult subjects. Results showed that the H152C GBP labeled with BADAN is capable of measuring TG and can be used for noninvasive glucose sensing.
\end{abstract}

Keywords: glucose binding protein, biosensor, BADAN, transdermal glucose

\section{INTRODUCTION}

Current FDA-approved blood glucose devices are based on biocatalytic elements such as glucose oxidase [1-5], glucose dehydrogenase [6] and hexokinase [7]. An alternative technology for glucose sensing employs bioaffinity elements such as the glucose binding protein (GBP) [8-13]. GBP is a member of a diverse group of transport proteins from Gram-

*To whom correspondence should be addressed leah@umbc.edu negative bacteria such as E. coli. Unlike enzymes, GBP does not require other reactants and co-factors. It exhibits high binding sensitivity, specificity and affinity to glucose. The binding equilibrium is straightforward, simple, reversible, and generates no reactive byproducts. Signal transduction arises from a change in conformation of the protein upon binding with glucose, and could be quantified through a polarity-sensitive fluorescent dye, which can differentiate the conformations of GBP. 
The binding constant $\left(K_{\mathrm{d}}\right)$ of GBP for glucose is in the micromolar level, making GBP suitable for the detection of low glucose concentrations such as in transdermal glucose flux in permeated skins. The capability of GBP to measure transdermal glucose has been demonstrated [14, 15]. Transdermal glucose (TG) measurement has gained interests due to its noninvasiveness in nature and its potential in medical diagnosis on challenged patients.

Efforts have been made to increase the binding constant to millimolar levels by studying different mutants of GBP to enable methods that can complement blood glucose levels [16, 17]. A GBP mutant (L255C) had been applied for measurement of TG $[14,15]$. In this paper, a bioengineered GBP (H152C) was prepared and characterized as a recognition element for TG measurement. This mutant has a polyhistidine tag that allows for quicker purification and provides a handle for protein immobilization.

\section{EXPERIMENTAL}

Materials. D-Glucose, $\mathrm{NaH}_{2} \mathrm{PO}_{4}, \mathrm{Na}_{2} \mathrm{HPO}_{4}$, $\mathrm{NaH}_{2} \mathrm{PO}_{4} \cdot \mathrm{H}_{2} \mathrm{O}$, N,N-dimethylformamide, $\mathrm{KH}_{2} \mathrm{PO}_{4}$ and Coomassie Brilliant Blue solution were acquired from Sigma-Aldrich (St. Louis, MO). BADAN (6-bromoacetyl-2-dimethylaminonaphthalene) was obtained from Molecular Probes (Eugene, OR). Slide-A-lyzer dialysis casettes were obtained from Thermo Scientific (Rockford, IL). Sephadex G-25 fine were from GE Healthcare (Bio Sciences, AB). Luria-Bertani (LB) medium, ampicillin, isopropyl-2-Dthiogalactopyranoside (IPTG), guanidium chloride (GuHCl), Tris-hydrochloride and urea were from Fisher Scientific. LB medium supplemented by antibiotics $(100 \mu \mathrm{g} / \mathrm{mL}$ ampicillin) was used to allow growth of cells. His Pur Ni-NTA resin and tris(2-carboxyethyl) phosphine (TCEP) were obtained from Thermo Scientific (Rockford, IL). All chemicals were used without further purification. Plasmids were created and purchased from Life Technologies.
Modified E. coli (BL21 DE3 strain) containing the plasmid (GBP H152C-pET303 CT His) was used as source of GBP. It was constructed in the laboratory by molecular cloning of $E$. coli (BL21 DE3 strain). Pre-constructed mutant (GBP H152C) was suspended in water and underwent transformation with BL 21 competent cells. Clones were taken for the mutant and glycerol stocks were made and inoculated.

Preparation of H152C GBP mutant. The H152C GBP was expressed, separated and purified as described previously $[10,11,13]$ with some modifications. The GBP was overexpressed at the periplasmic space by growing the modified $E$. coli cells in LB media. The cell growth was measured at the end of $3 \mathrm{~h}$ by determining its optical density at $600 \mathrm{~nm}$ using the spectrophotometer (Agilent technologies). At 0.4 optical density, expression of GBP was induced by adding $500 \mu \mathrm{L}$ of $1 \mathrm{M}$ isopropyl-2D-thiogalactopyranoside (IPTG) and grown for $4-5 \mathrm{~h}$ at $37^{\circ} \mathrm{C}$ at $225 \mathrm{rpm}$ agitation.

Bacterial cells were lysed through sonication for $10 \mathrm{~min}$ in a beaker containing ice using the probe sonicator (Fisher Scientific Sonic Dismembrator Model 500). Affinity chromatography was performed in two columns packed with $5 \mathrm{~mL}$ of equilibrated Ni-NTA agarose resin (Thermo Scientific).

Sodium dodecyl sulfate polyacrylamide gel electrophoresis (SDS-PAGE) was performed to verify the size, presence and purity of GBP. The concentration of the total protein of the isolated GBP was determined using Bradford Protein Assay. The highly pure fractions were dialysed using $20 \mathrm{mM}$ phosphate $\left(\mathrm{NaH}_{2} \mathrm{PO}_{4}\right.$ and $\mathrm{Na}_{2} \mathrm{HPO}_{4}$ ) buffer, $\mathrm{pH} 7.4$ at $4^{\circ} \mathrm{C}$.

The GBP was labeled with environmentally sensitive fluorophore, BADAN at the single cysteine mutation at position 152 following the manufacturer's recommended labeling procedure. The fluorophore was covalently 
attached to the cysteine mutation and known to be responsive to glucose $[11,16]$. Unreacted BADAN was removed by size exclusion chromatography column, Sephadex G-25 fine resin. The extent of labeling was determined from the GBP concentration and optical density of protein with dye. The following equation was used for the calculation of the extent of labeling (1):

$$
\text { Extent of labelling }=\frac{\text { mole dye }}{\text { moleprotein }} * 100=\frac{A x}{\varepsilon} * \frac{M W \text { protein }}{\text { proteinconc }\left(\frac{m g}{m L}\right)} * 100
$$

where $A_{x}$ is the absorbance value of the dye, BADAN at the absorption maximum wavelength, $\varepsilon$ is the molar extinction coefficient of the dye at the absorption maximum, which is 20000 and MW is the molecular weight of protein, which is $33310 \mathrm{~g} / \mathrm{mol}$.

The purified protein was dialysed in $100 \mathrm{mM}$ phosphate buffer, $\mathrm{pH}$ 7.5. The final product was $0.22 \mu \mathrm{m}$ filter-sterilized and stored at $4^{\circ} \mathrm{C}$.

Fluorescence measurements. The fluorescence intensities of BADAN-labeled GBP in the absence and presence of D-glucose in $1 \times$ PBS buffer were measured on a 96-well SpectraMax plate reader (Molecular Devices, Sunnyvale, CA). BADAN was excited at $400 \mathrm{~nm}$, with the maximum fluorescence emission $\left(\mathrm{Em}_{\max }\right)$ at $550 \mathrm{~nm} .200 \mu \mathrm{L}$ of GBP solution was added to each of the designated wells. Glucose standards or samples $(5.0 \mu \mathrm{L})$ were then added to each of the wells. The plate was gently shaken for $5 \mathrm{~s}$, and the intensities were measured 4 times. All measurements were made following the same instrumental conditions: excitation wavelength $400 \mathrm{~nm}$, emission wavelength $550 \mathrm{~nm}$, excitation and emission slit width $5 \mathrm{~nm}$, PMT detector voltage $750 \mathrm{~V}$, and average time $0.1 \mathrm{~s}$.

Standard solutions were prepared by dissolving D-glucose ( $>99.5 \%$ purity) from Sigma-Aldrich (St. Louis, MO) in $1 \times$ PBS, pH 7.4. A $1 \mathrm{mM}$ glucose solution, $\mathrm{pH} 7.5$ was used as a stock solution. The stock solution was then diluted to the following concentrations: $1,2,4,6,8,10$,
20, 50, 100, and $200 \mu \mathrm{M}$. Fluorescence intensities of GBP in the presence of glucose were plotted against glucose concentration $(\mu \mathrm{M})$ to attain the calibration curve.

The mean fluorescence readings were calculated from the four readings. Measurements are reported as normalized fluorescence intensity calculated as:

$$
\frac{(F-F o)}{F_{O}}
$$

where the $F$ and $F_{0}$ were the fluorescence intensities of GBP in the presence and absence of glucose, respectively.

The Varian Cary Eclipse fluorescence spectrophotometer was used to measure the fluorescence spectra. BADAN was excited at $390 \mathrm{~nm}$ with a slit width of $5 \mathrm{~nm}$. The emission spectra were measured in the range of 400 $650 \mathrm{~nm}$ with the maximum fluorescence emission $\left(\mathrm{Em}_{\max }\right)$ occurred approximately at $540 \mathrm{~nm}$, using the following conditions: high PMT detector voltage, average read time $0.10 \mathrm{~s}$, excitation filter auto and emission filter open.

Reusability (Reversibility) of the glucose binding protein. To check the possibility of BADAN-labeled GBP as a reversible biosensor, previously used GBP was recovered after the assay and studied for its reusability. To remove the bound glucose, the used GBP solution was injected into a Slide-A-lyzer dialysis cassette, which was then dialyzed in $1 \times$ PBS buffer for $6 \mathrm{~h}$ in a cold room. Afterwards, the $1 \times$ PBS buffer was replaced with fresh buffer and the GBP was dialyzed for another $6 \mathrm{~h}$. The GBP solution was transferred from the dialysis cassette to a sterile glass vial and filtered-sterilized. The recovered GBP solution was tested with glucose standard solution and the results were compared with the fresh GBP solution. The dialysis and recovery steps were repeated several times to see whether the GBP response remains the same. 
Determination of the binding constant of GBP. The binding constant $K_{d}$ of the GBP and its maximum glucose binding were calculated by fitting the data of fluorescence intensities (a.u.) at different glucose concentrations $(\mu \mathrm{M})$ to binding-saturation curves using Prism 6 (GraphPad Software, San Diego, CA, USA).

Measurement of transdermal glucose. Samples for transdermal glucose measurement were collected from healthy adult subjects, specifically from the skin of the fingers. The sampling protocol involved washing the hands with soap and water and followed by a distilled water rinse. The finger was then submerged in an agitated $20 \mathrm{mM}$ phosphate buffer in a beaker for $5 \mathrm{~min}$. The buffer was kept at constant temperature of $37^{\circ} \mathrm{C}$ using a jacketed beaker and continuous circulating water bath. Buffer temperature was monitored using an electronic thermometer. The washing step was followed by drying of the finger for 2 min with filtered air. Washing and drying steps are important to remove the residual glucose from the stratum corneum. This was to ensure that the collected sample is the glucose diffusing through the skin at time of collection. The five-minute increased temperature wash was also optimized [20].

Collection of the transdermal glucose sample was done by inverting a $1.5 \mathrm{~mL}$ Eppendorf tube containing $250 \mu \mathrm{L}$ of $20 \mathrm{mM}$ phosphate buffer at room temperature on the same finger for $5 \mathrm{~min}$. The total sampling time was $12 \mathrm{~min}$. The sample was collected and stored at $-80^{\circ} \mathrm{C}$. About $20 \mu \mathrm{L}$ TG samples were added to $200 \mu \mathrm{L}$ of the GBP solution. The fluorescence intensities were measured as previously described for the glucose standard solutions and the change in intensities were calculated against GBP without samples. The TG concentrations in the samples were calculated from the calibration curve.

To induce larger blood glucose changes, subjects were subjected to an oral glucose tolerance test. Samples for transdermal glucose measurement were collected from healthy adult subjects who had been fasting overnight. Two TG samples were collected during the fasting stage at about $30 \mathrm{~min}$ interval. After taking $75 \mathrm{~g}$ glucose, samples were then collected from the same subjects at 30 min time intervals for $2 \mathrm{~h}$. These steps capture the increase and steady decrease of glucose levels in the subject's body after consuming glucose.

Measurement of blood glucose. The blood glucose (BG) levels of the subjects were measured concurrently with the transdermal glucose. Corresponding BG levels were determined using a commercially available glucometer (ReliOn ${ }^{\mathrm{TM}}$ Confirm glucose meter). The BG level was measured on the same finger where TG was collected.

\section{Results AND DisCUSSION}

H152C GBP preparation. The H152C mutant of the glucose binding protein used in the experiments contained a polyhistidine tag, which allows for ease of purification. It was isolated from the lysate of the bacterial cells of modified E. coli by means of sonication and affinity chromatography. The SDS-PAGE of the purified GBP showed two thick bands at the $34 \mathrm{kDa}$ position consistent with the size of the GBP [8] (Fig. 1).

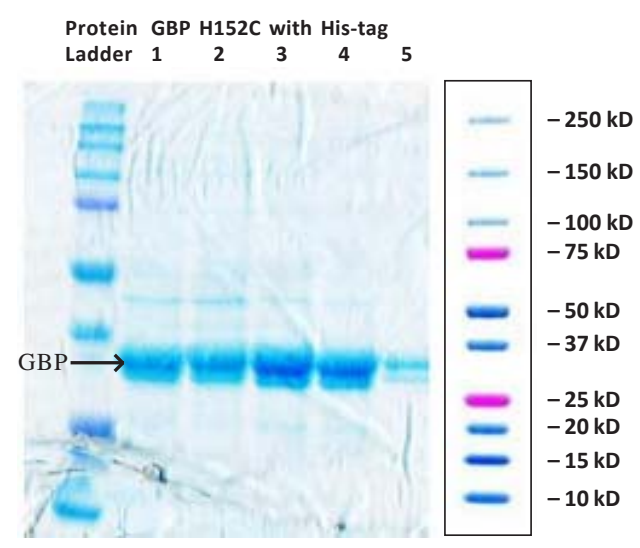

Figure 1. SDS-PAGE results showing the presence of H152C GBP 
The protein had a total concentration of $8.5 \mu \mathrm{M}$ and the calculated labeling extent of proteinbound BADAN was found to be $83.17 \%$.

Fluorescence of BADAN-labeled GBP. When the GBP labeled with BADAN was excited at $400 \mathrm{~nm}$, the maximum emission spectra occurred at approximately $540 \mathrm{~nm}$. Addition of saturating concentration of glucose (42 mM) to GBP resulted in an increase in fluorescence intensity of $228 \%$. Figure 2 shows the change in the fluorescence spectra of the protein in the absence and in the presence of glucose.

BADAN, a polarity sensitive dye, was reacted to the cysteine mutation at position 152 near the glucose-binding site in GBP. The observed

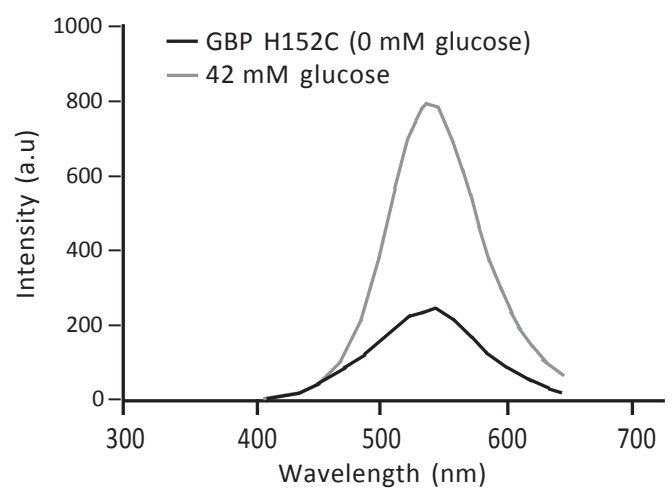

Figure 2. Emission spectra of GBP labeled with BADAN showing the increase in fluorescence intensity upon addition of glucose

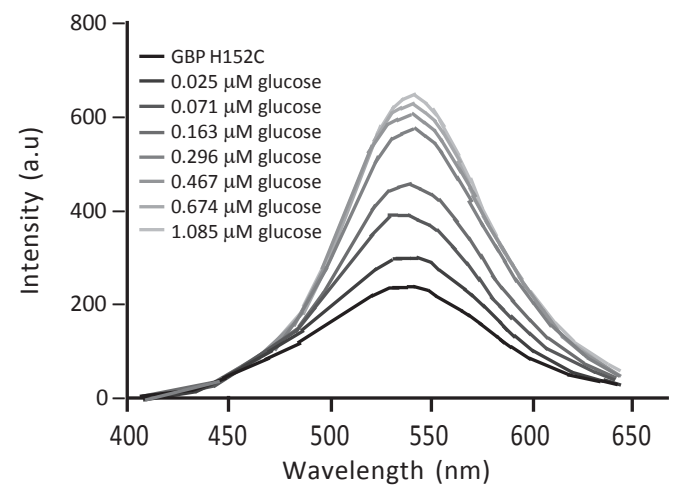

Figure 3. Emission spectra of BADAN-labeled GBP with increasing glucose concentrations increase in fluorescence intensity upon binding with glucose is due to the increased hydrophobicity around this site brought about by the closing of the two globular domains of the protein around glucose [18].

The fluorescence intensity of the BADANlabeled GBP increased with increasing glucose concentrations, varying significantly at low concentrations and only slightly at the higher concentrations of 0.674 and $1.085 \mu \mathrm{M}$ glucose (Fig. 3). A linear behavior occurred at the concentration range of $0.030-0.460 \mu \mathrm{M}$ (combine Fig. 4 and Fig. 5). Within this range, the GBP displayed good sensitivity $\left(1.68 \mu \mathrm{M}^{-1}\right)$ to glucose concentration and is most useful for

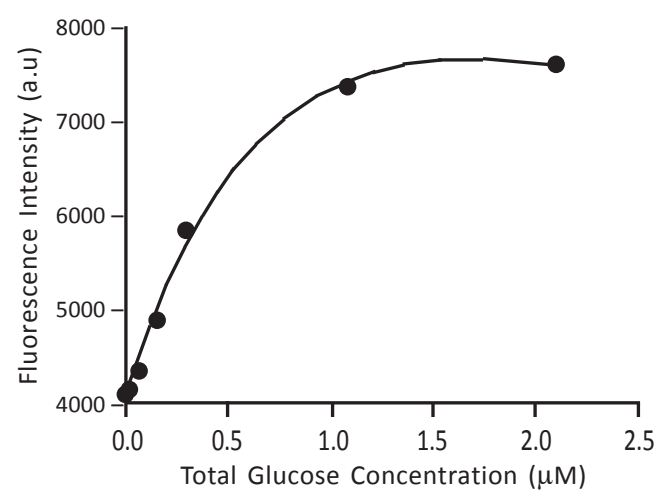

Figure 4. Fluorescence intensity of GBP as a function of total glucose concentration $(\mu \mathrm{M})$ $(n=4)$

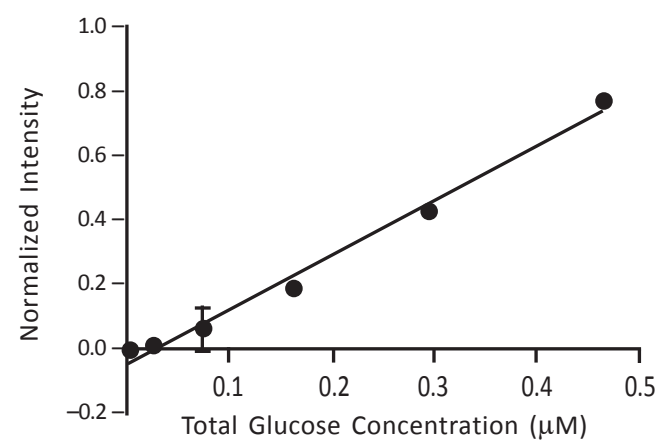

Figure 5. Linear range of calibration curve $(n=4)$ 
glucose measurement. The limit of detection of the assay (based on $3 \mathrm{~s}$ ) is $0.030 \mu \mathrm{M}$.

\section{Binding constant of the GBP and calibration} curve. The binding constant, $K_{d}$ of GBP H152CBADAN was found to be $1.124 \pm 0.236 \mu \mathrm{M}$ (Fig. 4). The apparent $K_{\mathrm{d}}$ was slightly lower compared from previous work, $2.35 \mathrm{mM}$ [18]. The binding constant, can be calculated by fitting experimental results from GBP response corresponding to different glucose concentrations to the binding isotherm (2):

$$
\Delta F=\frac{\Delta F \max [S]}{(K d+[S])}
$$

where $\Delta F$ is the normalized signal change at any ligand concentration, $\Delta F_{\max }$ is the normalized signal change at saturating ligand concentration, $[S]$ is the concentration of the ligand in free state and $K_{\mathrm{d}}$ is the binding constant. This equation along with equations for single binding equilibria and mass balance produce the following equation (3):

$$
\frac{\Delta F \max }{\Delta F}=1+\frac{K d}{[S] t-\frac{\Delta F}{\Delta F \max }[E] t}
$$

where $[\mathrm{E}]_{\mathrm{t}}$ and $[\mathrm{S}]_{\mathrm{t}}$ are the total concentrations of GBP and glucose respectively. The experimental results can be analyzed with

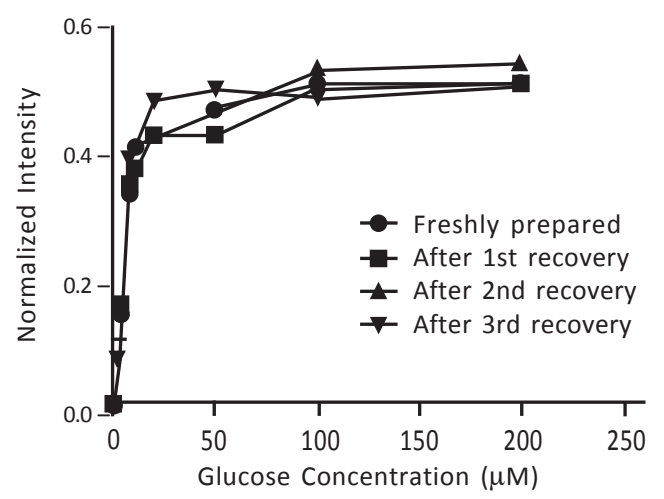

Figure 6. Reusability test of the BADAN-labeled H152C GBP $(n=4)$ nonlinear regression and the best values for " $\mathrm{F}_{\max }$ and $K_{\mathrm{d}}$ can be determined.

Reusability of the glucose binding protein. Reusability tests showed that the calibration curves did not change significantly after several recoveries (Fig. 6). These tests only proved that the GBP could be used many times, which could be considered as a potential reversible and reusable sensor [19].

Transdermal glucose measurement. Prior to the collection of TG sample, the finger was subjected to washing and drying in order to remove the existing glucose in the stratum corneum. These steps ensure that the collected glucose is the TG diffusing through the skin. Previous study showed that the temperature of the washing buffer and drying step are important parameters. An increase in temperature of washing buffer decreased the washing time required - from an initially 15-min wash at room temperature [15] to 5 -min at $37^{\circ} \mathrm{C}$ [20]. Table 1 shows the optimized parameters for sampling and analysis.

The TG concentrations in the collected samples were determined from a previously prepared calibration curve (Fig. 5). The results of the TG measurements for samples collected at different times during fasting and after intake of glucose are shown in Fig. 7 together with the results of BG measurements. It could be seen that TG levels follow the same trend as the BG. However, TG concentration had an average lag time of 49 min for individuals 1 and 2 . A peak value of

Table 1. Optimized Parameters for Noninvasive Transdermal Glucose Sampling and Analysis

\begin{tabular}{l|c}
\hline \multicolumn{1}{c|}{ Parameter } & Optimized value \\
\hline Wash time & 5 min [20] \\
\hline PBS Buffer temperature & $37^{\circ} \mathrm{C}[20]$ \\
\hline Drying time & 2 min [15] \\
\hline Sampling time & 5 min [15] \\
\hline Volume of PBS buffer & $250 \mu \mathrm{L} \mathrm{[14,15]}$ \\
\hline Volume of GBP & $200 \mu \mathrm{L}$ \\
\hline
\end{tabular}



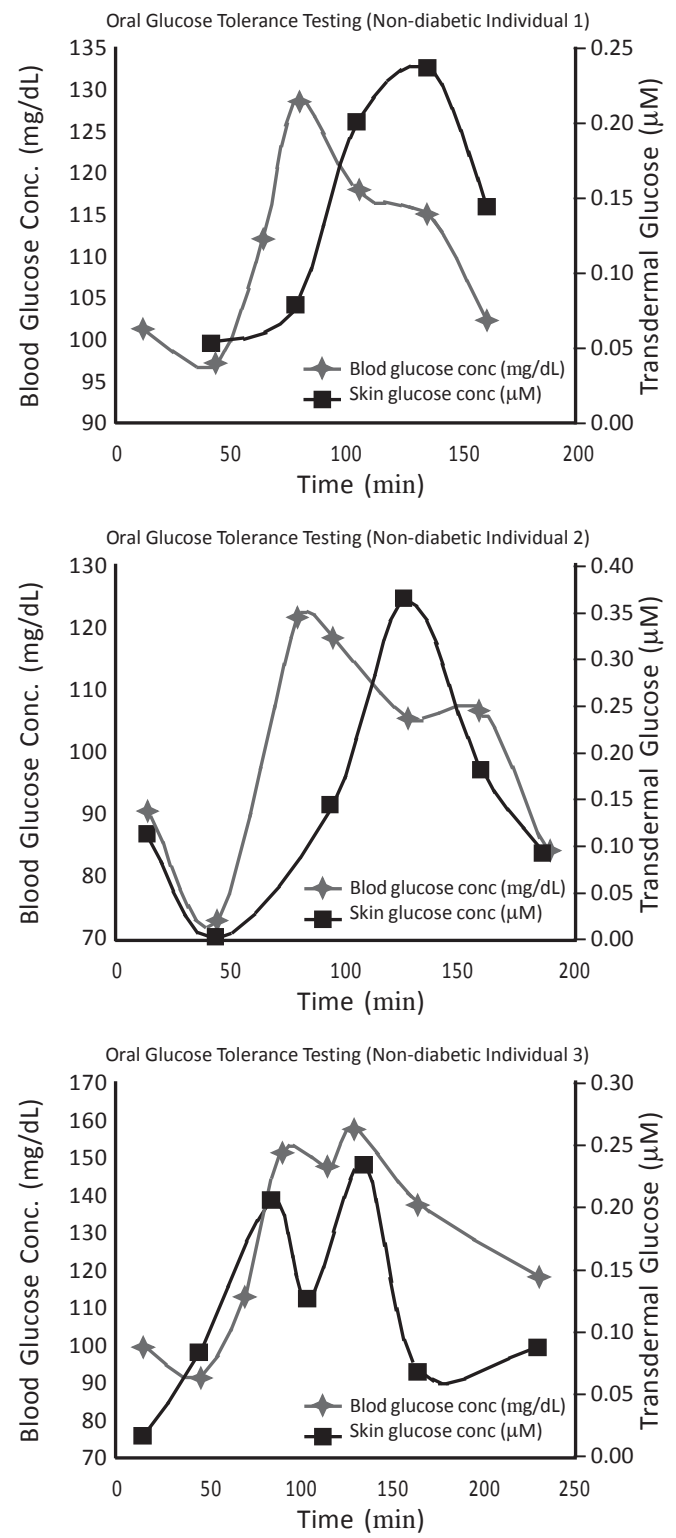

Figure 7. Comparison of TG and BG levels of healthy adult subjects from their Oral Glucose Tolerance Tests (OGTT) (Individuals 1-3)

$0.24-0.37 \mu \mathrm{M}$ were observed for the TG concentrations and 122-152 for the BG levels. A lag is expected in skin glucose samples because of the time required for ingested glucose to circulate to the blood, the tissues and then through the skin. Further investigation is needed to account for the lag time. However, the results for individual 3 did not show a lag time, which can be associated with the age of individual. These results showed a correlation exists between TG and BG.

\section{Conclusion}

A BADAN-labeled mutant of GBP (H152C) was synthesized, prepared and characterized. It had a $K_{d}$ in the micromolar levels indicating its capability to detect low TG concentrations. Fluorescence intensities increased markedly upon addition of glucose. There is a correlation between the measured transdermal glucose and blood glucose levels with a lag of TG behind blood glucose.

\section{ACKNOWLeDgment}

The authors acknowledge Science, Technology, Research and Innovation for Development (STRIDE) of United States Agency for International Development (USAID) for Cristina Tiangco's support. They would also like to thank KarunaSri Mupparapu for the GBP preparation training, Chandrasekhar Gurramkonda for the construction of H152C plasmid, Sean Najmi and Chisom Nwaneri for helping with the experimental work.

\section{REFERENCES}

[1] Khan AY, Noronha SB, \& Bandyopadhyaya R. Superior performance of a carbon-paste electrode based glucose biosensor containing glucose oxidase enzyme in mesoporous silica powder. Advanced Powder Technology 2016; 27:85-92. doi: 10.1016/j.apt.2015.11.003

[2] Barsan MM, Pifferi V, Falciola L, \& Brett CMA. New CNT/poly(brilliant green) and CNT/poly(3,4ethylenedioxythiophene) based electrochemical enzyme biosensors. Analytica Chimica Acta 2016; 927:35-45. doi: 10.1016/j.aca.2016.04.049

[3] Hervás Pérez JP, López-Ruiz B, \& LópezCabarcos E. Synthesis and characterization of microparticles based on poly-methacrylic acid with glucose oxidase for biosensor applications. Talanta 2016; 149:310-318. doi: 10.1016/ j.talanta.2015.11.053 
Tiangco C, Brown S, Sevilla F III, Rao G, \& Tolosa L | Acta Manilana 64 (2016)

[4] Devasenathipathy R, Mani V, Chen SM, Huang ST, Huang TT, Lin CM, Hwa KY, Chen TY, \& Chen BJ. Glucose biosensor based on glucose oxidase immobilized at gold nanoparticles decorated graphene-carbon nanotubes. Enzyme and Microbial Technology 2015; 78:40-45. doi: 10.1016/j.enzmictec.2015.06.006

[5] Pahurkar VG, Tamgadge YS, Gambhire AB, \& Muley GG. Glucose oxidase immobilized PANI cladding modified fiber optic intrinsic biosensor for detection of glucose. Sensors and Actuators B-Chemical 2015; 210:362-368. doi: 10.1016/ j.snb.2014.12.125

[6] D 'auria S, Cesare N Di, Gryczynski Z, Gryczynski I, Rossi M, \& Lakowicz JR. A Thermophilic Apoglucose Dehydrogenase as Nonconsuming Glucose Sensor. Biochemical and Biophysical Research Communications 2000; 274:727-731. doi: 10.1006/bbrc.2000.3172

[7] Hussain F, Birch DJS, \& Pickup JC. Glucose sensing based on the intrinsic fluorescence of sol-gel immobilized yeast hexokinase. Analytical Biochemistry 2005; 335:137-143. doi: 10.1016/ j.ab.2005.01.016

[8] Ge X, Tolosa L, \& Rao G. Dual-labeled glucose binding protein for ratiometric measurements of glucose. Analytical Chemistry 2004; 76:14031410. doi: 10.1021/ac035063p

[9] Amiss TJ, Sherman DB, Nycz CM, Andaluz SA, \& Pitner JB. Engineering and rapid selection of a low-affinity glucose/galactose-binding protein for a glucose biosensor. Protein Science 2007; 16:2350-2359. doi: 10.1110/ps.073119507

[10] de Lorimier RM, Tian Y, \& Hellinga HW. Binding and signaling of surface-immobilized reagentless fluorescent biosensors derived from periplasmic binding proteins. Protein Science 2006;15:1936-1944. doi: 10.1110/ps.062261606

[11] Khan F, Gnudi L, \& Pickup JC. Fluorescencebased sensing of glucose using engineered glucose/galactose-binding protein: A comparison of fluorescence resonance energy transfer and environmentally sensitive dye labelling strategies. Biochemical and Biophysical Research Communications 2008; 365:102-106. doi: 10.1016/j.bbrc.2007.10.129

[12] Scognamiglio V, Aurilia V, Cennamo N, Ringhieri P, Iozzino L, Tartaglia M, Staiano M, Ruggiero G, Orlando P, Labella T, Zeni L, Vitale A, \& D'Auria $\mathrm{S}$. D-galactose/D-glucose-binding Protein from Escherichia coli as Probe for a Non-consuming Glucose Implantable Fluorescence Biosensor. Sensors 2007; 7:2484-2491. doi: 10.3390/ s7102484
[13] Fonin AV, Stepanenko OV, Povarova OI, Volova CA, Philippova EM, Bublikov GS, Kuznetsova IM, Demchenko AP, \& Turoverov KK. Spectral characteristics of the mutant form GGBP/H152C of D-glucose/D-galactose-binding protein labeled with fluorescent dye BADAN: influence of external factors. Peer J 2014; 2:e275. doi: 10.7717/peerj. 275

[14] Ge X, Rao G, Kostov Y, Kanjananimmanont S, Viscardi RM, Woo H, \& Tolosa L. Detection of trace glucose on the surface of a semipermeable membrane using a fluorescently labeled glucosebinding protein: a promising approach to noninvasive glucose monitoring. Journal of Diabetes Science and Technology 2013; 7:412.

[15] Kanjananimmanont S, Ge X, Mupparapu K, Rao G, Potts R, \& Tolosa L. Passive Diffusion of Transdermal Glucose: Noninvasive Glucose Sensing Using a Fluorescent Glucose Binding Protein. Journal of Diabetes Science and Technology 2014; 8:291-298. doi: 10.1177/ 1932296813519994

[16] Khan F, Saxl TE, \& Pickup JC. Fluorescence intensity- and lifetime-based glucose sensing using an engineered high-Kd mutant of glucose/ galactose-binding protein. Analytical Biochemistry 2010; 399:39-43. doi: 10.1016/ j.ab.2009.11.035

[17] Saxl T, Khan F, Ferla M, Birch D, \& Pickup J. A fluorescence lifetime-based fibre-optic glucose sensor using glucose/galactose-binding protein. Analyst 2011; 136:968-972. doi: 10.1039/ COANOO430H

[18] Pickup JC, Khan F, Zhi Z-L, Coulter J, \& Birch DJS. Fluorescence intensity- and lifetime-based glucose sensing using glucose/galactosebinding protein. Journal of Diabetes Science and Technology 2013; 7:62-71. doi: 10.1177/ 193229681300700108

[19] Lam H, Kostov Y, Rao G, \& Tolosa L. Low-cost optical lifetime assisted ratiometric glutamine sensor based on glutamine binding protein. Analytical Biochemistry 2008; 383:61-67. doi: 10.1016/j.ab.2008.08.018

[20] Brown S. Transdermal Glucose Sensor for Neonates Using Glucose Binding Protein (Master's Thesis). (University of Maryland Baltimore County, 2015) 